\title{
LAS PINTURAS MURALES DE SAN JUAN BAUTISTA DE ALARCÓN. DE LO SAGRADO A lo PROFANO, de lo profano a lo sagrado
}

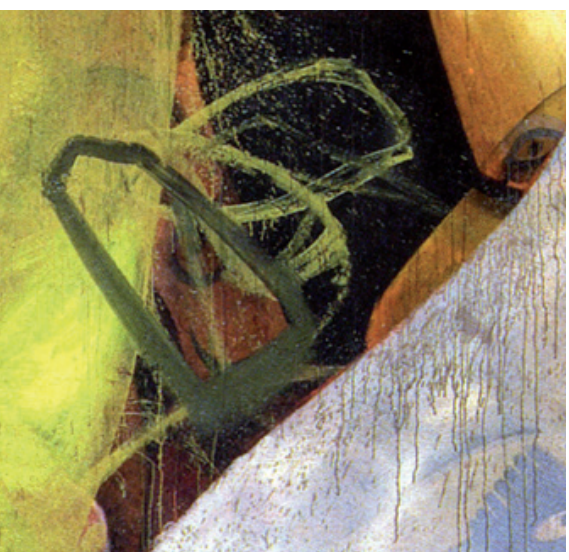

\author{
Esteban Fernández-Cobián
}

The mural paintings of St. John the Baptist of Alarcon.

From the sacred to the profane, from the profane to the sacred

Boletín Académico. Revista de investigación y arquitectura contemporánea
Escuela Técnica Superior de Arquitectura. Universidade da Coruña
elSSN 2173-6723
www.boletinacademico.com
Número 5 (2015)
Páginas 61-72
Fecha de recepción 25.10.2014
Fecha de aceptación 02.12.2014

https://doi.org/10.17979/bac.2015.5.0.1039

\section{Resumen}

El arte ha sido siempre un aliado imprescindible para la liturgia católica, ya que tiene la potencialidad de transformar lo material en espiritual. Es el milagro que los artistas pueden realizar. Pero si un verdadero artista es capaz de transformar una tabla en un icono - el material profano en algo espiritual y sagrado_-, ¿podría ese mismo artista recorrer el camino inverso? ¿Podría profanar lo sagrado, y humanizar -o incluso animalizar - el espíritu? En nuestra opinión, eso es lo que ha ocurrido en la iglesia de san Juan Bautista de Alarcón con los misteriosos murales realizados por un joven y desconocido pintor, Jesús Mateo, entre 1994 y 2002, y que han sido patrocinados por la UNESCO. A través del relato de su génesis y desarrollo, este artículo pretende arrojar luz sobre este fenómeno mediático, aportando un punto de vista novedoso que se apoya en fuentes inéditas.

\begin{abstract}
Art has always been an indispensable ally for the Catholic liturgy, as it has a unique potential: to transform the material into the spiritual. It is the miracle that artists can perform. But if a true artist is able to transform a table into an icon - the profane material into something spiritual and sacred-, could the same artist go the opposite way? Could profaning the sacred, and humanizing -or even downgrade to a category of animal- spirit? In our opinion, that is what has happened in the church of St. John the Baptist of Alarcón by the mysterious murals, made by an unknown and young painter, Jesus Mateo, between 1994 and 2002, and sponsored by UNESCO. Through the story of its genesis and development, this article seeks to illuminate this media phenomenon, providing a new perspective that is based on unpublished sources.
\end{abstract}

\section{Palabras clave}

Jesús Mateo, Alarcón, Pinturas murales, Creación, UNESCO

\section{Keywords}

Jesús Mateo, Alarcón, Mural Paintings, Creation, UNESCO 


\section{INTRODUCCIÓN}

Hace algunos años, la iglesia de san Juan Bautista de Alarcón (Cuenca) se convirtió en el centro de un inesperado fenómeno mediático. La causa del revuelo eran unas imágenes sorprendentes, oníricas, que mostraban una especie de bestiario moderno realizado durante siete largos ańos, en soledad, por un joven y desconocido pintor local: Jesús Carlos Mateo Cano (1971). La noticia no hubiera tenido apenas eco si a la calidad de la obra no se hubiera añadido el dato de que habían sido ejecutadas en una iglesia desacralizada, que desde el 3 de diciembre de 1997 contaban con el Patrocinio de la UNESCO, y que se había creado una fundación aneja. ¿Qué estaba pasando en Alarcón? ¿Cual era el origen de esas pinturas? ¿Quién era Jesús Mateo?

Con el paso del tiempo se fueron conociendo algunos detalles adicionales, que el propio autor mostró en un sitio web donde, de manera somera, explicaba la génesis de esta obra ${ }^{1}$. Posteriormente, también se realizó una cuidada monografía en dos volúmenes titulada "El Noveno día de la Creación», en la que se recogen numerosas fotografías de los murales de Alarcón y algunos de los ensayos más importantes que se han escrito sobre ellos ${ }^{2}$. De alguna manera, el propio título ya es descriptivo de lo que un espectador siente al entrar en la iglesia: que está ante el momento inicial de una nueva creación del universo. Así lo expresaba Fernando Arrabal:

Si el mural de Jesús Mateo fuera una epopeya contaría la vida de las primeras fieras del paraíso terrenal.

Si fuera manual de historia, relataría la trasmutación de la energía en estrellas. El mural de Jesús Mateo emana del universo 3 .

Sin embargo - como por otra parte suele ser habitual-, ni las explicaciones del autor ni las de los analistas convocados para contextualizar la obra resultan del todo convincentes. Por eso, partiendo de la correspondencia del sacerdote José Luis Valverde Zarco con el autor y con el párroco que encargó el proyecto, recientemente fallecido, así como de la visita directa a la obra, este artículo pretende aportar algunas claves que ayuden a entender el origen real - no míticode estas pinturas fascinantes, así como aventurar una hipótesis hermenéutica sencilla, aunque alternativa a las ya dadas por otros. Se trata de mostrar la pervivencia del proyecto iconográfico inicial, profundamente religioso, en el resultado final. Y dejar las sugerentes derivas esotéricas -iniciáticas, en general; órficas, en concreto- apuntadas por otros autores, para una ocasión más favorable.

\section{EL DESAFÍO}

La villa de Alarcón se levanta en un promontorio de La Manchuela conquense como verdadera plaza fuerte, rodeada por el profundo foso que forma un meandro del río Júcar. Está unida a tierra tan sólo por un paso defendido por una espléndida torre del homenaje, convertida hoy en Parador Nacional. En esta villa medieval existen notables edificios civiles y hasta cinco iglesias, lo que contrasta con una población que apenas supera en la actualidad los doscientos habitantes. Esto nos habla de un esplendoroso pasado y de un debilitado presente. Sólo el encanto del enclave, la belleza de su arquitectura y las páginas gloriosas de la historia de la Reconquista que allí se escribieron podrían librarla del olvido en el que también están sumidos muchos otros pueblos de la zona.

En Alarcón trabajaba un benemérito párroco, Luis Martínez Lorente. Era un hombre de cuerpo menudo pero espíritu enorme. Sus palabras destilaban saber de muchas cosas, especialmente de arte. Sabía leer las antiguas construcciones y desentrańar los secretos de sus constructores. Conocía por qué éstos elegían un lugar y no otro para edificar las iglesias, por qué las apoyaban en un número determinado de columnas, y cómo decidían qué imágenes debían esculpirse en sus hornacinas o pintarse en sus retablos. Daba la impresión de que entre el sacerdote y aquellos constructores no hubiera secretos. Y seguramente, la escuela en la que había aprendido todo lo que sabía eran las cinco iglesias de este pueblo, al que fue enviado como párroco tras su ordenación sacerdotal hace más de cuarenta años.

Los caprichos del azar hicieron coincidir en una velada al viejo párroco de Alarcón y a un joven pintor conquense sin experiencia, ni obra, ni curriculum, Jesús Mateo, que tenía entonces veintitrés años (Fig. 01). Era el 11 de junio de 1994. Ambos habían sido invitados a celebrar la primera comunión de uno de los hijos de la familia Del Pozo Sanz, propietaria del manantial de aguas minerales Solán de Cabras. La estampa-recordatorio del evento la había dibujado Mateo. Durante la comida, el párroco comenzó a desafiar al joven, diciéndole que era fácil pintar unos centímetros cuadrados de cartulina, pero que él tenía un lienzo de decenas de metros cuadrados de pared esperando a un pintor que se atreviera a trabajar en ellos. El pintor 

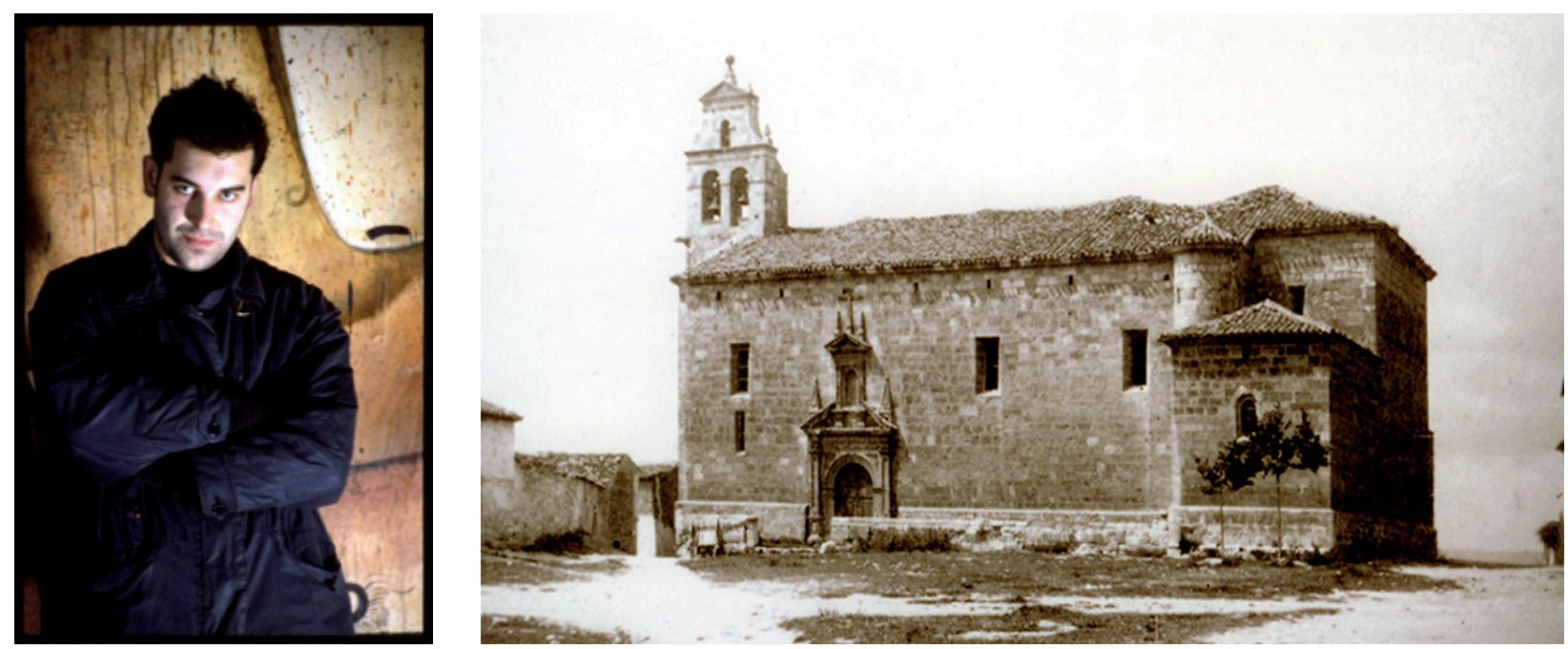

01 Jesús Mateo Cano, 1998

02 Estado de la antigua iglesia de san Juan Bautista, Alarcón (Cuenca), a finales del siglo XIX

mordió el anzuelo, y la familia propietaria de la famosa marca de agua embotellada, testigo del desafío, ofreció la primera ayuda. Luego vendría el permiso del obispado, el patrocinio de la UNESCO y las ayudas económicas necesarias para una obra de proporciones excesivas para un pueblo de doscientos habitantes. Otros pintores se interesaron, cedieron cuadros para subastas benéficas y se constituyó una asociación. Y así, del lance del sabio párroco al inexperto pintor, surgió la aventura de las pinturas murales de Alarcón.

\section{LA IGLESIA DE SAN JUAN BAUTISTA}

El lienzo que el sacerdote ofrecía al pintor no era otro que el interior de la iglesia de san Juan Bautista, uno de los cinco templos de la villa (Fig. 02). Un edificio renacentista, de líneas rectas y puras - más herreriano que el propio Juan de Herrera-, orientado canónicamente, y que había sido restaurado durante los años setenta, tras haber sufrido el hundimiento de su bóveda después de más de dos siglos de abandono y pérdida de su dedicación litúrgica. Por lo tanto, el templo estaba vacío y en desuso, con sus paredes blancas, inertes, como a la espera (Fig. 03).

El párroco y el joven pintor idearon un plan iconográfico que suponía plasmar en el muro norte escenas de la vida de san Juan Bautista, y en el sur, momentos de la vida de Jesucristo. El muro oriental (donde se ubicaba el antiguo presbiterio, ya sin altar, siquiera) recogería el encuentro de ambos personajes, el Precursor y el Precedido, en la escena del bautismo de Cristo en el Jordán. Todo sería ejecutado en el personal estilo pictórico de Jesús Mateo, en aquel momento a caballo entre lo abstracto y lo figurativo.

Sin embargo, conforme los bocetos iban ocupando sus lugares, el viejo edificio iba influyendo en los ánimos del artista y del párroco, cambiándolos, haciéndoles variar completamente su plan inicial. De alguna manera, aquella iglesia, ya sin uso litúrgico, les estaba pidiendo algo distinto a una representación de la vida del Bautista: les exigía un contenido y unas formas diferentes. Lo contaban el propio párroco y el pintor, respectivamente:

«Cuando Jesús C. Mateo se decidió a invadir de color el espacio interior de la antigua parroquia de san Juan Bautista de Alarcón, el propósito primero era desarrollar un programa pictórico sobre las vidas de san Juan y la de Cristo en paralelo. Como la iglesia dejó de tener el cuidado de los hombres y quedó sometida al tiempo, que la convirtió en una ruina de empleo residual, no había imperativos litúrgicos que restringieran la libertad del pintor. Era un antiguo edificio recuperado en el año 1970, sin otra pretensión que la de completar el conjunto monumental [de la villa], sin devolverlo a su antigua función litúrgica $»^{4}$.

«Fue ese día cuando conocí el escenario o soporte que serviría para albergar mi obra pictórica. Realmente no contaba con ningún proyecto concreto. Lo cierto es que fue el espacio, la arquitectura, sus dimensiones y su estado de semiabandono lo que determinó mi particular intervención. Fue un feliz condicionante y una feliz coincidencia»s. 

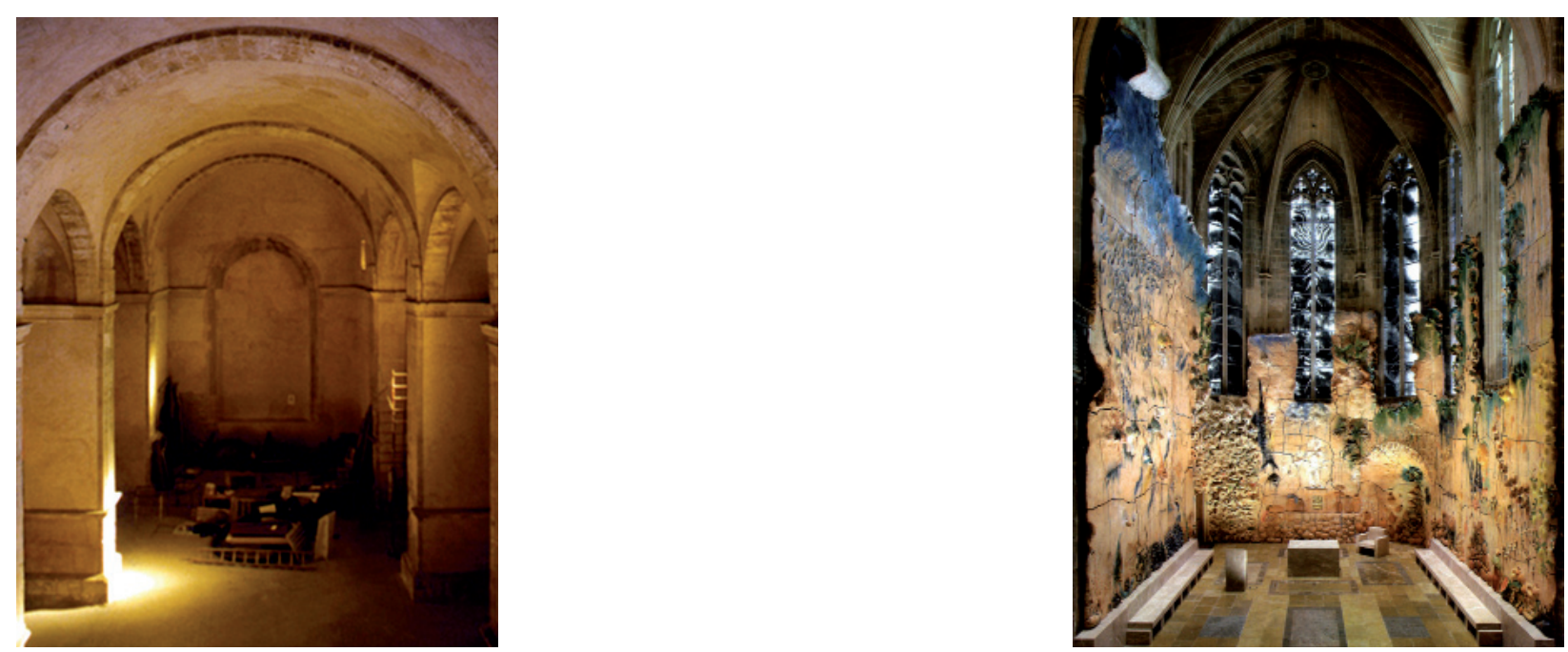

03 Interior del edificio al comienzo de las obras, 1998

04 Miquel Barceló, Capilla del Santísimo de la Catedral, Palma de Mallorca, 2001/06

El párroco consiguió los necesarios permisos oficiales - permisos no siempre fáciles, dado el carácter contemporáneo de la intervención y el tipo de edificio histórico en el que se iban a ejecutar-, incluido el de su obispo, que entonces era José Guerra Campos. Y libres ya de los condicionantes externos, se pusieron manos a la obra. Una obra que duró más de siete años, con sus días y sus noches, porque al pintor le gustaba trabajar de noche para evocar mejor, quizá, la oscuridad de la caverna prehistórica en la que acabó convirtiéndose la iglesia de san Juan Bautista.

\section{UN ARTE AL SERVICIO DE LO SAGRADO}

No es mi intención adentrarme aquí en disertaciones acerca de la ancestral relación entre el arte y lo sagrado; sin embargo, dado que las pinturas se han realizado sobre una antigua iglesia católica, sí resulta imprescindible hacer una breve reflexión acerca de la relación entre el arte y la liturgia católica ${ }^{6}$.

En la liturgia católica, la realidad sagrada que se celebra ha de expresarse necesariamente mediante signos y símbolos. Requiere la convocatoria de los sentidos para que el hombre pueda acercarse al misterio. $Y$ por eso despliega un ritual en el cual intervienen gestos y palabras, música y silencio, colores, olores y hasta sabores. Y aunque estas sensaciones son incapaces por sí mismas de abarcar la magnitud el misterio que evocan, todas ellas son necesarias para, al menos, intentar acceder a él.

Por eso, el arte ha sido siempre un aliado imprescindible para la liturgia. El papa Juan Pablo II decía que «para transmitir el mensaje que Cristo le ha confiado, la Iglesia tiene necesidad del arte. En efecto, debe hacer perceptible — más aún, fascinante- en lo posible, el mundo del espíritu, de lo invisible, de Dios» ${ }^{7}$. Esto es así porque el artista tiene una potencialidad única: la de transformar lo material en espiritual. Es el milagro que los artistas pueden obrar, y que llamamos arte.

Pero si un verdadero artista es capaz de transformar una tabla en un icono, una madera en un Cristo, o una piedra en un altar; en suma, si un auténtico artista tiene el poder de metamorfosear el material profano en algo espiritual y sagrado, ¿podría ese mismo artista recorrer el camino inverso? ¿Podría profanar lo sagrado y humanizar —o incluso animalizar - el espíritu? Es muy posible que la respuesta a estas preguntas sea afirmativa. Y que, precisamente, eso sea lo que haya ocurrido en la iglesia de san Juan Bautista de Alarcón, aunque no se haya consumado del todo, como veremos.

No cabe duda de que las pinturas murales de Jesús Mateo son osadas para haber sido ejecutadas en un templo; quizá, incluso, transgresoras. Pero se puede hacer una lectura religiosa de ellas - tanto desde el punto de vista perceptivo como desde el iconográfico-, algo que no se ha realizado hasta ahora ${ }^{8}$. Conversando con José Luis Valverde y respondiendo a la pregunta de si en su trabajo había tenido un plan religioso de fondo, Mateo explicó lo siguiente:

«La iglesia lleva desacralizada más de doscientos años. Por ello la significación y el concepto general de la obra es profano. Te remito a las decenas de textos y ensayos 

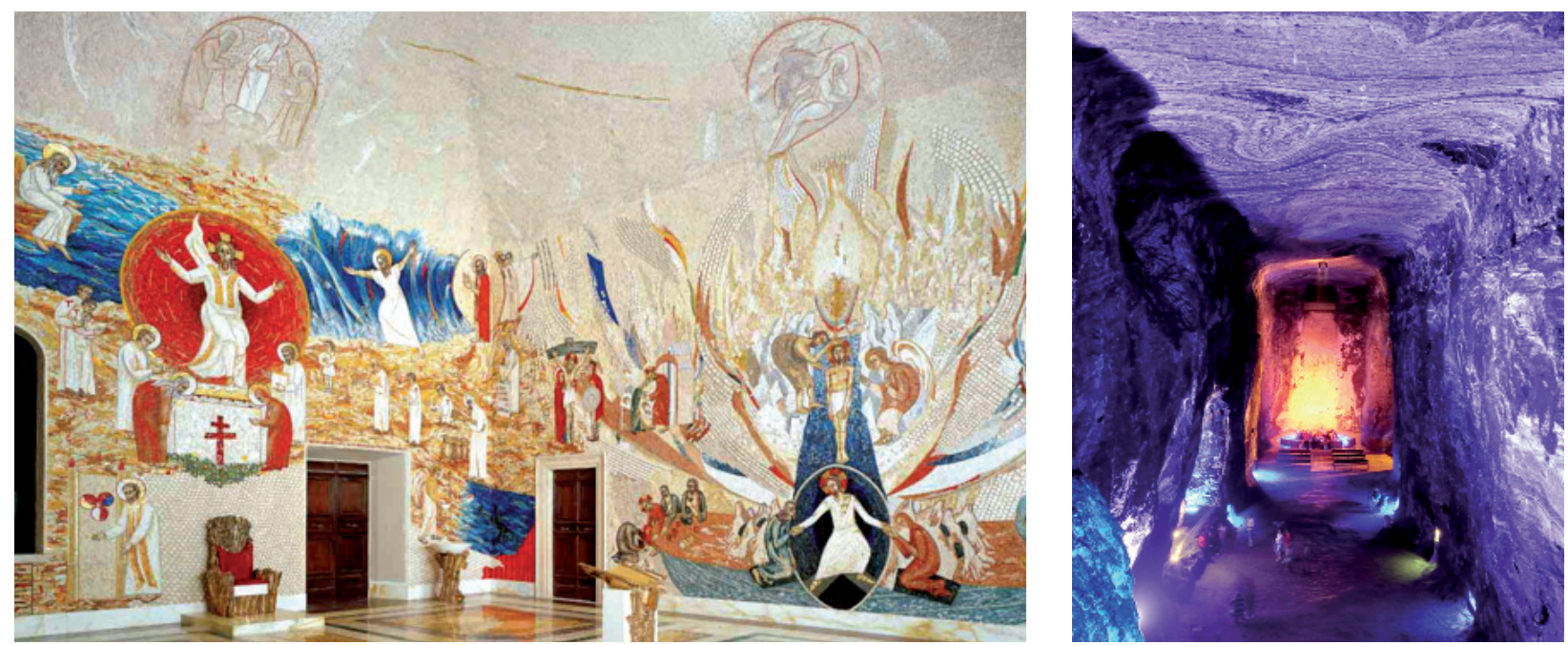

05 Marco Iván Rupnik, Capilla Redemptoris Mater, Ciudad del Vaticano, 1996/99 06 Alfredo Rodríguez Orgaz, Catedral de la Sal, Zipaquirá (Colombia), 1950/54

colgados en la web y publicados en varios libros. Pese a ello, no olvidé el carácter primigenio del edificio. Por ello, sí hay un contenido (ligeramente velado u oculto) de significación religiosa. No olvidemos que yo también soy católico. Aunque no hay que dejar de lado todo lo que te indico acerca del edificio - su funcionalidad, la desacralización, el paso del reino de la gracia al reino de la cultura, etc.—, hay conceptos religiosos o trascendentes que sí están presentes en la obra. El nacimiento y la muerte. El génesis. El árbol de la vida. Los pecados capitales. Los signos zodiacales. La bóveda celeste. El bien y el mal. La luz y las tinieblas, el Tótem, ídolo o DIOS que hay descrito en la cabecera (en líneas blancas): JESÚS. Junto a él, la imagen de un san Juan Bautista desrealizada [sic] junto a una mancha azul que simboliza el agua, la purificación, el inicio...»"

Así las cosas, parecía claro que, en realidad, lo que había pretendido Jesús Mateo en Alarcón era recorrer el camino inverso a lo que tantos otros artistas pretendieron. Si éstos tomaban una materia inerte —vacía de significado- y la transformaban en algo sagrado, Mateo había tomado un espacio antańo sagrado para devolverlo a su condición natural y profana primera. No solamente desde el punto de vista jurídico-canónico (el edificio ya estaba desacralizado de hecho), sino también desde el punto de vista de su manifestación sensorial, de su apariencia (a pesar de su temática explícitamente religiosa). La obra de arte debería ser el hecho mismo de manifestar esta circunstancia.

A la vista del resultado obtenido - una especie de Capilla Sixtina prehistórica, que a nadie deja indiferente, y que permitiría ciertos paralelismos con otras obras recientes, como la Capilla del Santísimo de la Catedral de Palma de Mallorca (Fig. 04), la capilla Redemptoris Mater en el Vaticano (Fig. 05) o incluso con la Catedral de la Sal, en Zipaquirá, Colombia (Fig. 06)—, se ha discutido la oportunidad de haber realizado esta obra en un edificio del siglo XVI.

Para muchos analistas de las pinturas de Alarcón, Jesús Mateo ha convertido el antiguo templo herreriano en una especie de cueva prehistórica o incluso platónica, en la que el hombre primitivo, todavía sin respuestas a sus interrogantes religiosos, mira asombrado - asustado quizá- al mundo que le rodea. Un mundo en el que la vida lucha por abrirse paso, en constante tensión entre el nacimiento y la muerte, el bien y el mal, el suelo y el cielo.

Pero antes de determinar si su pintura es arte sacro o es otra cosa, lo que no puede discutirse es que en esta iglesia hay algo que sigue evocando el misterio. Pero ¿de qué misterio se trata? El misterio evocado no es otro que el momento primigenio, la explosión creadora de la vida, generada desde abajo - como desde su raíz- por un tótem (aún no lo podemos llamar Dios) y observada por el hombre, que actúa como notario atónito de lo que ocurre a su alrededor.

Es evidente que las pinturas de Alarcón no están al servicio de la liturgia católica ni siquiera del misterio cristiano. Más bien retrotraen esos contenidos revelados al estadio anterior a la Revelación, al estadio mítico en el que el tótem, el zodíaco y los temas originales de la vida y la muerte, del bien y del mal, son convocados ${ }^{10}$. 


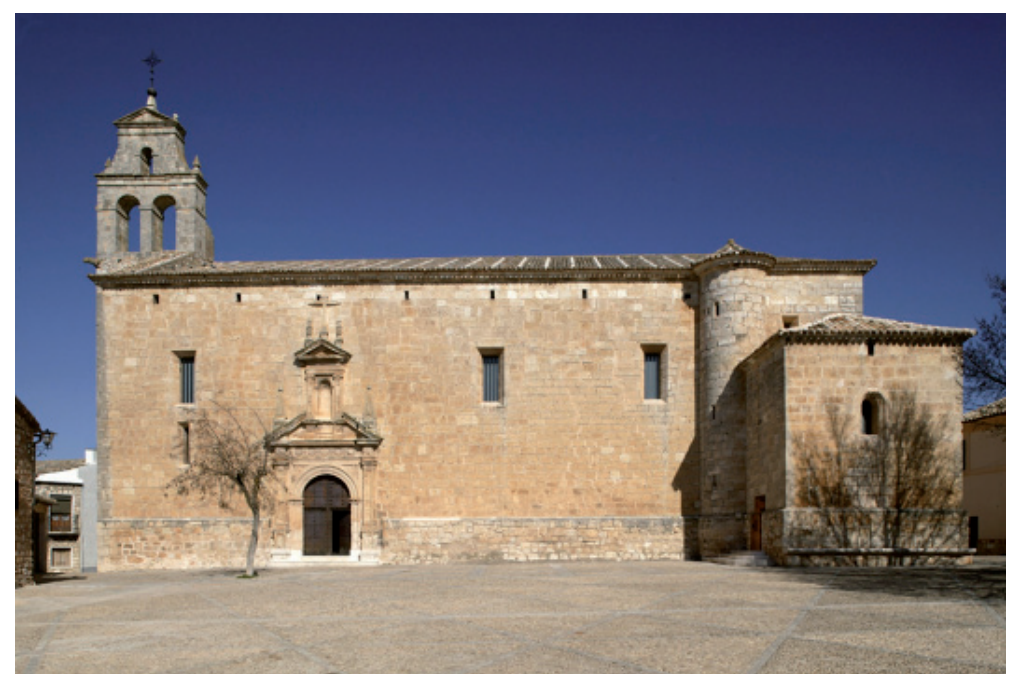

07 Vista general de la antigua iglesia al finalizar de las obras (2005); a la derecha, la antigua sacristía, donde se sitúa la entrada

Con todo, nos podríamos preguntar si ese propósito profanador se ha conseguido realmente. Algunos de los escritos sobre Alarcón así lo afirman. Pero desde nuestro punto de vista, la clarificación de este aspecto fundamental de la obra requiere un análisis un poco más detallado. En este momento sólo parece claro que la intervención de Mateo se sitúa en la línea de lo que Juan Pablo II recordaba en su Carta a los artistas: «Nadie mejor que vosotros, artistas, geniales constructores de belleza, puede intuir algo del pathos con el que Dios, en el alba de la creación, contempló la obra de sus manos ${ }^{\prime 1}$. Analicemos, pues, brevemente, las pinturas.

\section{LAS PINTURAS DE ALARCÓN}

Se accede a la iglesia por la antigua sacristía, situada al mediodía, que actúa como cámara de descompresión (Fig. 07). Desde allí, el visitante se zambulle en la caverna pictórica, entrando en ella por lo que en su día fue el presbiterio. Este simple hecho es la primera acción transgresora que se realiza en el edificio, ya que sólo los encargados del culto (sacerdotes o sacristanes) podían hacerlo cuando la iglesia estaba en funcionamiento. Hacia occidente se despliegan los murales, una oscura explosión de color donde innumerables formas fósiles —animales y vegetales- emergen, luchando entre sí por el espacio, en tensión por existir. No hay equilibrio entre ellas, ni obedecen a ningún orden aparente. Es más bien pura vida emergiendo del caos.

Luego, la vista se dirige hacia la bóveda, en la que la oscuridad está salpicada por puntos blancos que se corresponden con las constelaciones; también hay extraños animales alados en los cielos. $\mathrm{Al}$ fondo, el muro oeste exhibe el contraste entre una zona de tonos claros con otra de granates y negros. Y cuando el espectador se gira y fija la vista sobre el antiguo muro testero, se encuentra con un enorme rostro trazado con líneas blancas y con otro del color de la carne humana, con la boca abierta en grito de denuncia profética. El rostro de líneas blancas emerge desde el suelo pero tiene sus pies en el muro occidental, como si toda la nave del templo fuera su cuerpo, una suerte de raíz desde la que emanara esta explosión de vida.

Este primer rostro blanco es el que Jesús Mateo llama Tótem, Cristo o Dios (Fig. 08). Efectivamente, es una figura todavía sin perfilar, con los brazos en alto, la mano derecha alzada, chorreando como si estuviera mojada, como si tuviera en su mano el limo primigenio de la creación original. Junto a él, separado por una mancha azul que evoca el agua, se encuentra el otro rostro — sólo cabeza y brazos - señalando con una mano al tótem y sosteniendo en la otra un gallo - el animal encargado de anunciar la salida del sol- decapitado. Resulta obligado recordar que, en el boceto original, este muro estaba dedicado al encuentro de Jesús con Juan el Bautista en el río Jordán. Las referencias a esos dos protagonistas son claras en las dos figuras: por tanto, algo del proyecto inicial ha permanecido ahí, aunque velado.

Si continuamos el recorrido por la iglesia siguiendo un movimiento contrario al de las manecillas del reloj, nos encontramos en primer lugar con el muro septentrional. El lienzo que mira al norte es el muro en donde 

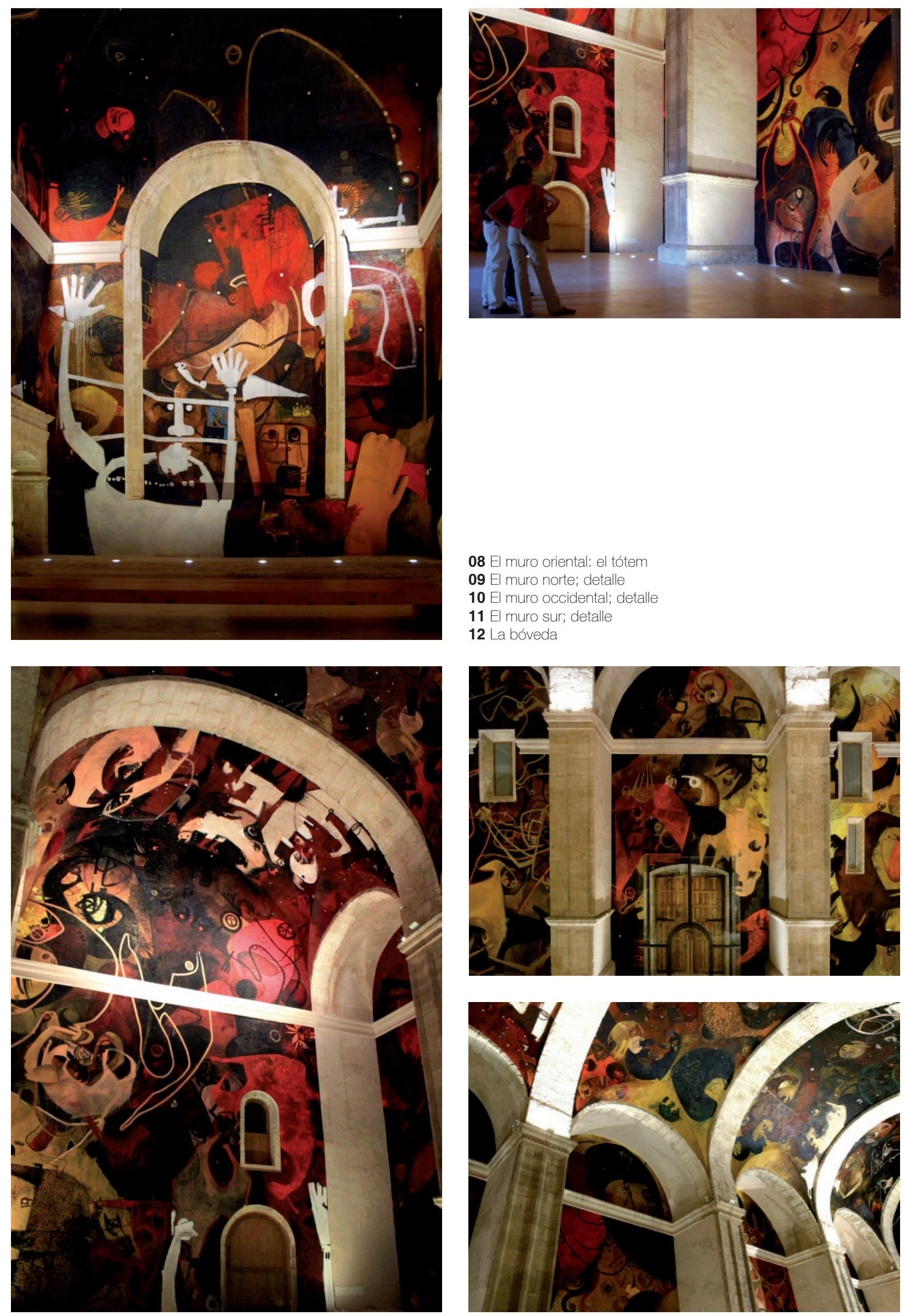

08 El muro oriental: el tótem

09 El muro norte; detalle

10 El muro occidental; detalle

$11 \mathrm{El}$ muro sur; detalle

12 La bóveda
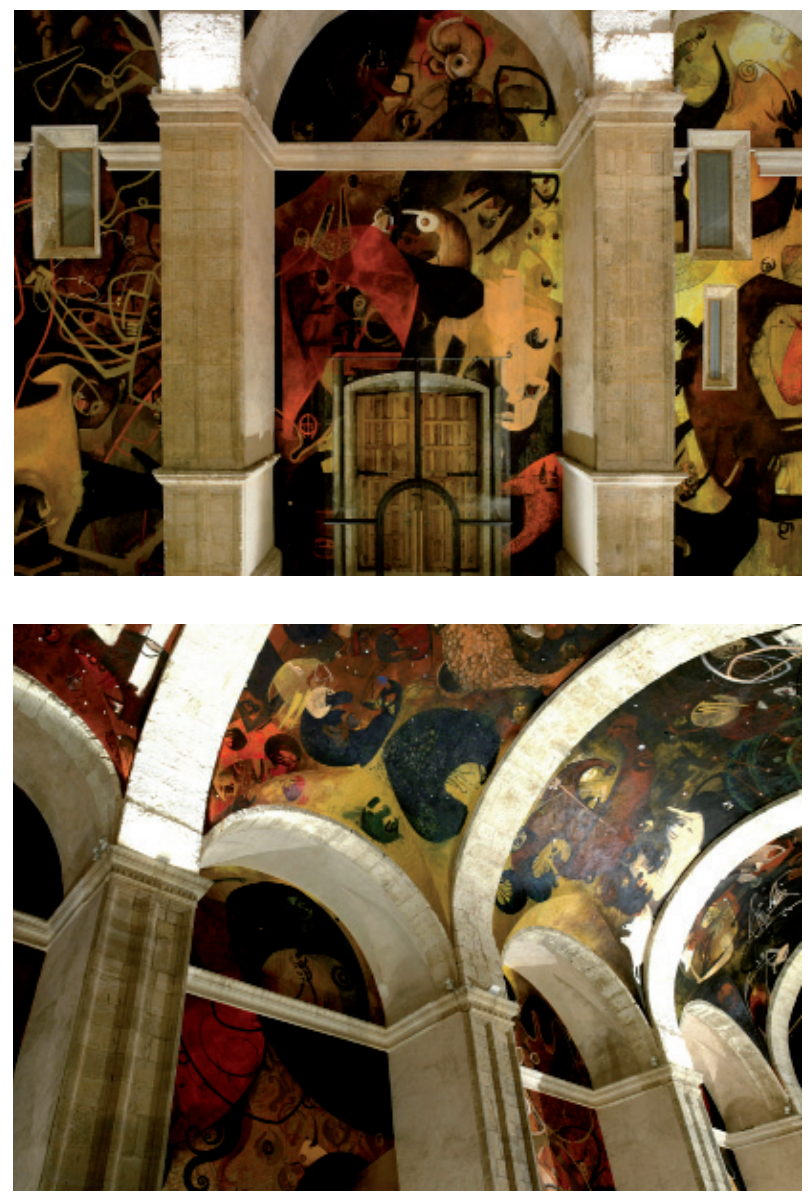


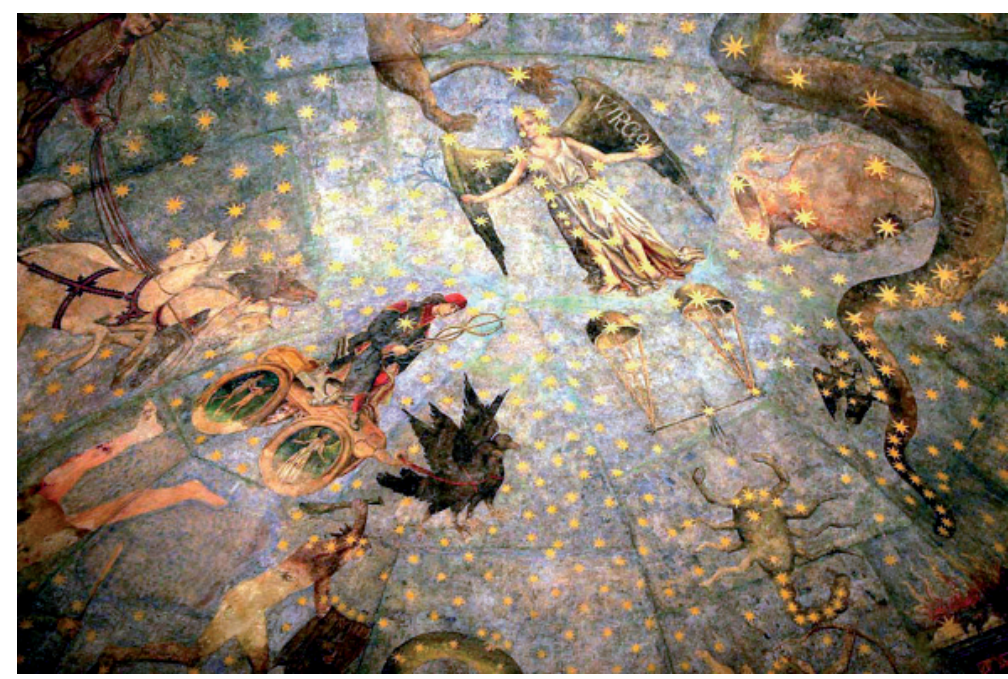

13 Fernando Gallego, El Cielo de Salamanca, Salamanca, 1481/86; detalle 14 En página siguiente. Animales fantásticos en el muro norte

Jesús Mateo comenzó a pintar, realizando en uno de los tramos una escena del esquema original: Juan Bautista en el desierto. El resultado no le convenció, y por eso la pintura fue evolucionando. Pero algunos fragmentos del dibujo original todavía permanecen allí, unas veces velados por dibujos sobrepuestos, otras transformados.

El pintor había leído en ese tiempo el libro de J.W. Schopf «La cuna de la vida»" ${ }^{12}$, un relato que narra, de manera novelada, los hallazgos más importantes acerca de los primeros seres vivos de la tierra. Hasta qué punto ese texto llegó a influir en su obra, es algo difícil de precisar. En cualquier caso, organismos primitivos, reptiles y alas de insecto hacen su aparición, a la vez que mamíferos evocadores del páramo donde Juan el Bautista habitaba (Fig. 09). El cordero joánico, recurrente en la iconografía cristiana, está —lógicamente- entre las formas de vida que surgen allí. También es significativa la presencia en este muro de un árbol - Mateo lo llama el Árbol de la Vida - que prolonga sus ramas curvas, de tramo en tramo, por todo este lienzo. Como recuerda Mircea Eliade, «los mitos de la búsqueda de la inmortalidad o de la juventud ponen en primer plano un árbol de frutos de oro o de follaje milagroso, árbol que se encuentra 'en un país lejano' (...) y que está defendido por monstruos (grifos, dragones, serpientes)»13.

Seguimos adelante. Según el libro del Génesis, Dios creó el mundo en seis días y el séptimo descansó. La tradición cristiana habla de un octavo día, el del tiempo inaugurado por Cristo tras su resurrección, un día que ya no tendrá ocaso ${ }^{14}$. El muro occidental —los antiguos pies de la iglesia, que en las iglesias medievales eran signo del mal y del demonio- es también aquí el lugar de la lucha entre ambos opuestos, entre la vida y la muerte (Fig. 10). Del suelo emergen los pies del tótem. Sobre él, animales y figuras contorsionadas se enfrentan a una parte superior oscura y tenebrosa. Una línea que recuerda a un hombre o a un ángel asciende desde la zona de colores claros — acaso la vida - con un gesto de victoria hacia las tinieblas superiores.

En el proyecto, los paños que se encuentran al sur se reservaban para la vida de Jesús. A primera vista, parece que la intención cristológica ha desaparecido. Priman aquí los grandes animales, naciendo unos de otros, en una actitud más serena (Fig. 11). Es como si ya el orden hubiera ido ganando terreno al caos y la muerte a la vida. Sin embargo, la aparente ausencia del plan cristológico inicial no es más que eso: mera apariencia. Cuando menos lo esperamos, en uno de los lunetos superiores encontramos el rostro de Cristo, tomado de manera literal del que se venera en Jaén como «Santo Rostro», y que el pintor había visto en un cuadro de la casa del párroco.

Finalmente, la última intervención de Jesús Mateo en Alarcón se produjo en la bóveda (Fig. 12). A la tierra recién creada le correspondían, también ahora, los cielos recién creados. Cielos mitológicos, zodiacales. El pintor recordó el Cielo de Salamanca, la bóveda celeste que Fernando Gallego ejecutó en el siglo XV en la universidad $^{15}$ (Fig. 13). Luego realizó un estudio astronómico de las constelaciones, y finalmente, buscó en el bestiario medieval los animales que simbolizan cada 


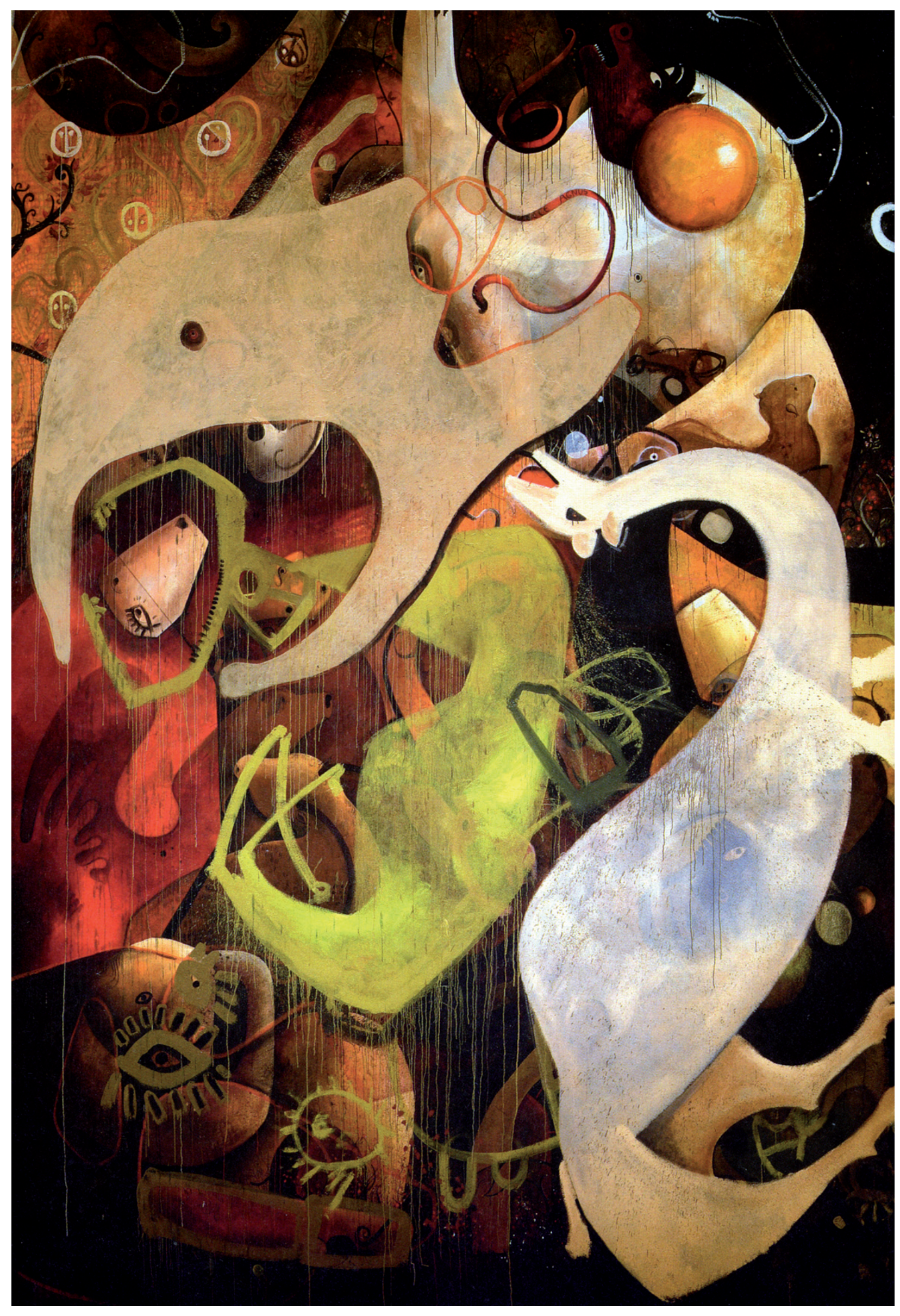


una de ellas (Fig. 14). De esta forma, «los doce signos, los doce meses, el año natural, los cuatro elementos, la noche, el día, las constelaciones, los fetos, los embriones, las estructuras primarias, el Sol, la Luna, la muerte y la vida, están contenidas en la bóveda, y por extensión en todo el proyecto. Todo forma parte de esta urna pictórica en la que se desarrolla una idea específica del hombre, del paso del tiempo, de la perennidad ${ }^{16}$.

\section{DE LO SAGRADO A LO PROFANO, DE LO PROFANO A LO SAGRADO}

El título de este artículo es «Las pinturas murales de Alarcón. De lo sagrado a lo profano, de lo profano a lo sagrado». En esta frase se recogen dos afirmaciones contrapuestas.

Según la primera, las pinturas de Jesús Mateo suponen la constatación plástica —y por ello, sensorial— de la devolución del espacio en el que se plasmaron (una antigua iglesia) a una situación profana previa: la que tenía el edificio antes de su consagración. La iglesia de san Juan Bautista habría regresado así del reino de la gracia, para el que fue construida, a un estadio anterior que podríamos denominar convencionalmente como reino de la cultura. Desde este punto de vista, lo único que habrían hecho las pinturas es ayudar a visualizar - manifestar - la desacralización que ya se había iniciado más de un siglo antes con la pérdida del uso litúrgico, la eliminación de los elementos celebrativos $y$, posteriormente, con la ruina material del edificio.

Pero en la segunda afirmación se sugiere que, en realidad, las pinturas también han hecho una suerte de viaje de regreso desde lo profano a lo sagrado. Un viaje que ha devuelto a los muros del templo una cierta capacidad de servir para aquello para lo que fueron levantados: acoger el misterio. Es verdad que en el ábside de Alarcón no vemos un Pantocrátor sino un tótem; es verdad que los personajes alados de la bóveda celeste no son ángeles sino fieras; es verdad que las pinturas de Mateo recuerdan más a los bestiarios románicos o a los jardines oníricos de Bruegel el Viejo o El Bosco que a la dulzura de los ángeles de Giotto o Fra Angélico. Pero también es verdad que el espacio conseguido por Mateo sobrecoge y plantea preguntas por lo que hay en el origen y en el destino de toda esa explosión de vida. Y esas preguntas, típicamente religiosas, son las que provocan el viaje de vuelta.
Por otra parte, todavía es posible dar un paso más en la valoración del conjunto mural. Hasta ahora, tan sólo nos hemos fijado en cómo afectan las pinturas a la condición sagrada - jurídica, aunque no fenomenológicamente, perdida- del espacio que ocupan. Hemos visto cómo afecta el contenido al continente. Pero ¿resulta indiferente que las pinturas de Mateo estén donde están? ¿Tendrían el mismo significado y producirían el mismo efecto en el espectador si se hubieran plasmado sobre lienzos o sobre las paredes - pongamos por caso- de un centro comercial o, incluso, de una iglesia contemporánea? La respuesta es un rotundo no.

Y esto es así porque al igual que ocurre con todos los fluidos y, en general, en el mundo del pensamiento recuérdese el dicho escolástico Quidquid recipitur, ad modum recipientis recipitur (lo que se recibe, se recibe según la forma del recipiente), los muros de la vieja iglesia de san Juan Bautista no son un soporte inerte. Sus medidas, sus proporciones, las perspectivas que se generan entre ellos tienen mucho que decir a las pinturas. Y cuando uno observa el conjunto, advierte que alrededor del caos de la vida emergente y en lucha que surge de los murales, esas pilastras, arcos, cornisas y bóvedas tienen una función ordenadora, aportan un sentido (Fig. 15).

Cuando Jesús Mateo pintó al tótem recorriendo todo el espacio de la iglesia, desde el testero hasta los pies, no buscaba nada más que poner su figura como llave del peculiar universo que había recreado, en el que entonces él era el único ser humano. No tenía pretensiones de trascendencia; sin embargo, podemos pensar que este mismo hombre sí que tiene este valor, ya que es su otra dimensión. Karl Rahner ha defendido que el hombre es el lugar de Dios, el sitio donde Él habita ${ }^{17}$. El párroco de Alarcón lo sabía. Y por eso, este edificio, al ser pintado por Jesús Mateo, ha invertido su sentido primordial: ya no es el lugar que el hombre busca para encontrarse con Dios - que es para lo que fue construido-, sino que ahora es el lugar al que Dios desciende para encontrarse con el hombre.

La elegante y ordenada estructura del edificio herreriano, liberada por la pintura de la adherencia de sus paredes, se convierte así en la nueva Jerusalén celestial, que desciende bella y radiante, al mundo caótico y contradictorio de los hombres. 
Notas

1 Cf. Pintura Mural de Alarcón, con acceso el 12/09/2013, http://muralalarcon.org/.

2 AAVV, Pinturas murales de Jesús Mateo en Alarcón. Vol. 1. El Noveno día de la Creación. Vol. 2. Ensayos y bocetos (Madrid: La Fábrica, 2006). Contiene textos de José Saramago, Ernesto Sabato, Gustavo Bueno, Fernando Arrabal, José Antonio Marina, Francisco Brines, José Vidal Beneyto, Federico Mayor Zaragoza, Antonio López, etc. Entre ellos, tal vez el más interesante a nuestros efectos sea el del filósofo Gustavo Bueno Martínez, «Más allá de lo Sagrado: un análisis del proyecto del mural de Jesús Mateo», 81-115 (disponible on-line en El Catoblepas 122 (2012): 2, con acceso el 24/10/2014, http://www. nodulo.org/ec/2012/n122p02.htm.

3 Fernando Arrabal Terán, en AAVV, El Noveno día, 21.

4 Texto manuscrito entregado por el párroco a José Luis Valverde Zarco (10/08/2010). Archivo personal.

5 Declaraciones del pintor a Juan Antonio Marina Torres, en Ensayos y bocetos, 53.

6 Sobre este tema, es interesante la lectura de las cartas y alocuciones que los últimos pontífices —Pablo VI, Juan Pablo II y Benedicto XVI— han dedicado a los artistas. Cf. por ejemplo, Pablo VI, «Volvamos, Iglesia y artistas, a la gran amistad», Arte Religioso Actual 1 (1964): I-IV; Juan Pablo II, Carta a los Artistas (1999), con acceso el 10/09/2013, http:/www.vatican.va/holy_father/john_paul_ii/letters/documents/hf_jp-ii_let_23041999_artists_sp.html; Benedicto XVI, Encuentro con los artistas (21 de noviembre de 2009), con acceso el 10/09/2013, http://www.vatican.va/holy_father/benedict_xvi/speeches/2009/november/documents/hf_ben-xvi_spe_20091121_artisti_sp.html.

7 Juan Pablo II, Carta a los Artistas, 12.

8 Existen textos breves y notas de prensa acerca de la obra de Alarcón y de la presentación del libro «El Noveno día de la Creación». Pueden verse, por ejemplo, Jesús Cotillas Díaz, «Las pinturas murales de Alarcón de Jesús Mateo», Añil 17(1999):40-41; Virginia Hernández Rueda, «Los sueños a veces, se cumplen", El Mundo (12/11/2007), con acceso el 24/10/2014, http:/www.elmundo.es/elmundo/2007/11/08/cultura/1194542344.html; Isabel Lafont Benzal, «Siete ańos en el andamio», El Páis (07/11/2007), con acceso el 24/10/2014, http://elpais.com/diario/2007/11/07/cultura/1194390002_850215. html; o María Jesús Burgueño Muñoz, «El Noveno día de la Creación. Pinturas murales de Jesús Mateo en Alarcón», Revista de Arte (30/10/2007), con acceso el 24/10/2014, http:/www.revistadearte.com/2007/10/30/el-noveno-dia-de-la-creacion-pinturas-murales-de-jesus-mateo-en-alarcon/.

9 Correo electrónico de Jesús Mateo a José Luis Valverde Zarco (15/06/2010). Archivo personal. Las mayúsculas son del propio Mateo.

10 Según mons. Giancarlo Ravasi, Presidente del Pontificio Consejo para la Cultura, algo parecido ha pretendido conseguir el primer pabellón para la Bienal de Venecia de la Santa Sede, titulado En el Principio (2013). Cf. La Santa Sede estrena pabellón en la Bienal de Venecia, con acceso el 12/09/2013, http:// www.news.va/es/news/la-santa-sede-estrena-pabellon-en-la-bienal-de-ven.

11 Juan Pablo II, Carta a los Artistas, 1.

12 Barcelona: Crítica, 2000.

13 Lo sagrado y lo profano (Barcelona: Labor, 1992): 128-129.

14 Los Padres de la Iglesia consideraban como santo el número ocho. Significaba para ellos la purificación del pecado, cosa que venía prefigurada por la costumbre de la circuncisión al octavo día. Quería significar también la perfección, ya que Cristo anunció ocho bienaventuranzas como suma de la perfección en la vida del cristiano. Pero, sobre todo, el ocho es el número de la resurrección, la cual tuvo lugar al octavo día, después del sábado (cf. San Ambrosio, al Sal 118, pról. 2).

15 Cf. José María Martínez Frías, El Cielo de Salamanca (Salamanca: Ediciones Universidad de Salamanca, 2006).

16 Extracto del diario de trabajo del autor citado por Marina en AA.VV., Ensayos y bocetos, 65.

17 Cf. AAVV, El Noveno día, 64

\section{La estructura, elemento que ordena el espacio}

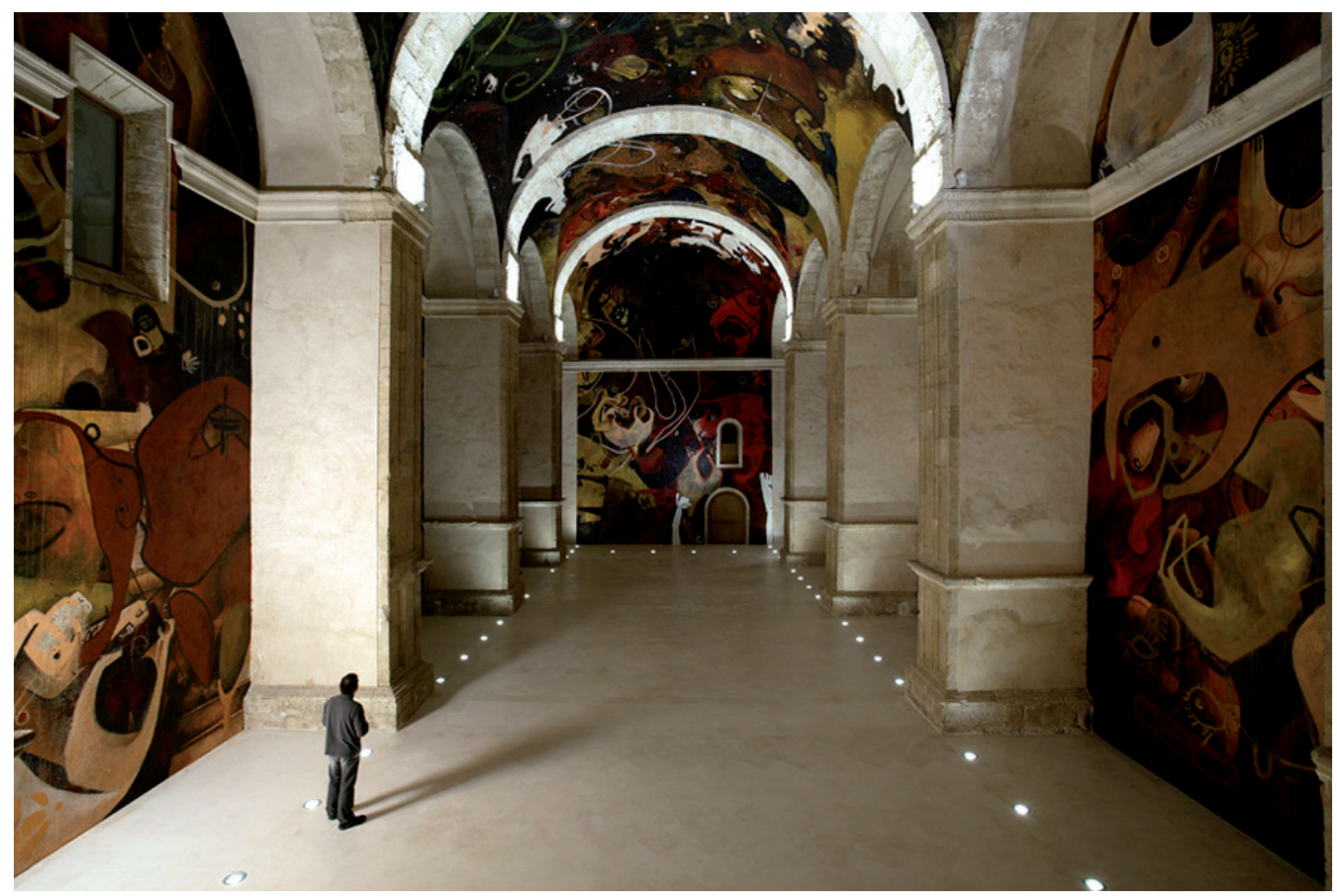


Procedencia de las ilustraciones

Fig. 01-10, 12-13 y 15. Archivo del autor.

Fig. 11 y 14. José Latova, AA.VV., Pinturas murales de Jesús Mateo en Alarcón. Vol. 1. El Noveno día de la Creación (Madrid: La Fábrica, 2006).

\section{Sobre el autor}

Esteban Fernández-Cobián (Vigo, 1969). Doctor en Arquitectura (2001, Premio CSIC). Profesor Contratado Doctor de la Escuela Técnica Superior de Arquitectura de la Universidade da Coruńa, Profesor Invitado de la Universitá di Bologna (2008) y de la Universidad Popular Autónoma de Estado de Puebla (2014), miembro del Comité Científico de la Fondazione Frate Sole (Pavia), es autor de las monografías Between Concept and Identity (2014), Escritos sobre arquitectura religiosa contemporánea (2013), Arquitecturas de lo sagrado. Memoria y proyecto (2009), El espacio sagrado en la arquitectura española contemporánea (2005), Fray Coello de Portugal, dominico y arquitecto (2001) y A Coruña. Guía de arquitectura (1998), así como de diversos artículos y ponencias en congresos. Ha coordinado las tres ediciones del Congreso Internacional de Arquitectura Religiosa Contemporánea (Ourense 2007 y 2009 , Sevilla 2013)

efcobian@udc.es 